\title{
Unidades fitofisionômicas em mesoescala no Pantanal Norte e suas relações com a geomorfologia
}

\author{
Ibraim Fantin-Cruz ${ }^{1,4}$, Pierre Girard ${ }^{2}$, Peter Zeilhofer ${ }^{3}$, \\ Walter Collischonn ${ }^{1}$ \& Cátia Nunes da Cunha ${ }^{2}$ \\ ${ }^{1}$ Instituto de Pesquisas Hidráulicas, Universidade Federal do Rio Grande do Sul - UFRGS, \\ Av. Bento Gonçalves, 9500, CP 15029, CEP 91501-970, Porto Alegre, RS, Brasil \\ ${ }^{2}$ Instituto de Biociências, Universidade Federal de Mato Grosso - UFMT, \\ CEP 78060-900, Cuiabá, MT, Brasil \\ ${ }^{3}$ Departamento de Geografia, Universidade Federal de Mato Grosso - UFMT, \\ CEP 78060-900, Cuiabá, MT, Brasil \\ ${ }^{4}$ Autor para correspondência: Ibraim Fantin-Cruz, e-mail: ibraimfantin@gmail.com
}

FANTIN-CRUZ, I., GIRARD, P., ZEILHOFER, P., COLLISCHONN, W. \& CUNHA, C.N. Meso-scale phytophysiognomic units in the Northern Pantanal and their relations with geomorphology. Biota Neotrop. 10(2): http://www.biotaneotropica.org.br/v10n2/en/abstract?article+bn00410022010.

\begin{abstract}
The purpose of this work was to characterize and quantify phytophysiognomic units at mesoscale and evaluate their relationships with flood intensity, flood duration and topography. The study was conducted at a $25 \mathrm{~km}^{2}$ Long-Term Sampling Site (LTSS), located within the floodplain of the Cuiabá River in the Pantanal of Mato Grosso. The phytophysiognomic units were determined from the supervised classification of CBERS 2B sensor CCD satellite images. The maps of flood intensity, flood duration and of topography were generated from the spatial interpolation of planialtimetric field surveys. Four phytophysiognomic units were identified; Campo inundável (flooded grassland) was the unit with the largest area of occurrence, followed by Cordilheiras (dense arboreal savanna), Landizal (seasonally flooded evergreen forest), and Cambarazal (monodominant Vochysia divergens Pohl. forest), respectively. Campo inundável is distributed mainly in areas of high flood intensity and duration and low topographic positions. Cambarazal predominates in areas of medium flood intensity and duration and intermediate elevation, Landizal in areas of high flood intensity and duration and low topographic position, whereas Cordilheiras are characterized by low flood intensity and duration and location in higher elevations. Statistical tests indicated that flood intensity is the main factor responsible for the mesoscale distribution of phytophysiognomic units in the northern Pantanal.
\end{abstract}

Keywords: flood intensity and duration, topography, floodplain vegetation, remote sensing, Cuiabá River, ecohydrology.

FANTIN-CRUZ, I., GIRARD, P., ZEILHOFER, P., COLLISCHONN, W. \& CUNHA, C.N. Unidades fitofisionômicas em mesoescala no Pantanal Norte e suas relações com a geomorfologia. Biota Neotrop. 10(2): http://www.biotaneotropica.org.br/v10n2/pt/abstract?article+bn00410022010.

Resumo: Este trabalho teve por objetivo caracterizar e quantificar as unidades fitofisionômicas em mesoescala e estabelecer suas relações com a intensidade e duração da inundação e com a topografia. $\mathrm{O}$ estudo foi realizado no Sítio de Amostragem de Longa Duração (SALD), implantado em uma área de $25 \mathrm{~km}^{2}$ localizado na planície de inundação do rio Cuiabá, Pantanal de Mato Grosso. As unidades fitofisionômicas foram determinadas a partir da classificação supervisionada de imagens CBERS 2B sensor CCD. Os mapas de intensidade e duração da inundação e topografia foram gerados a partir da interpolação espacial de levantamentos planialtimétricos de campos. Foi evidenciada a existência de quatro unidades, sendo o Campo (pastagem inundável) a unidade com maior área de ocorrência, seguido pelas Cordilheiras (savana arbórea densa), Landizal (floresta inundável sempre verde) e Cambarazal (floresta inundável monodominante de Vochysia divergens Pohl.) respectivamente. O Campo apresentou sua maior distribuição em áreas de alta intensidade e duração de inundação e topografia baixa. O Cambarazal predomina em áreas de intensidade média e duração e topografia alta, o Landizal em áreas com intensidade e duração alta e topografia baixa, enquanto as cordilheiras são caracterizadas por intensidade e duração baixa e topografia alta. Testes estatísticos indicaram que a inundação foi o principal fator responsável pela distribuição das unidades fitofisionômicas em mesoescala no Pantanal norte.

Palavras-chave: intensidade e duração da inundação, topografia, vegetação da planície de inundação, sensoriamento remoto, Rio Cuiabá, ecohidrologia. 


\section{Introdução}

O Pantanal é uma planície sazonalmente inundável, onde as flutuações anuais do nível de água regulam os processos ecológicos ali existentes (Junk et al. 1989, Neiff 1990). As diferenças locais da inundação (intensidade e duração), assim como as variações topográficas, modelam a paisagem e por consequiência a distribuição das unidades fitofisionômicas (Neiff 1990, 2001, Cunha et al. 2007). A ocorrência espacial de cada unidade é o resultado da combinação dos fatores acima citados, porém seus efeitos podem variar, determinando a ocorrência de diferentes tipos de unidades fitofisionômicas.

O gradiente espacial da inundação foi reportado como um dos principais fatores atuantes na distribuição e abundância das espécies vegetais na planície do Pantanal (Cunha \& Junk 2001, Zeilhofer \& Schessl 2000, Rebellato \& Cunha 2005, Damasceno-Junior et al. 2005, Arieira \& Cunha 2006).

Em outras planícies sul-americanas tem-se sugerido que a cota topográfica atua como fator na distribuição de espécies e padrões de comunidades vegetais (Ferreira \& Almeida 2005, Casco et al. 2005, Neiff et al. 2005), pois partem do princípio de uma relação linear entre a cota topográfica e a inundação, ou seja, variações topográficas determinam diretamente a intensidade e duração da inundação.

Partindo do pressuposto que a topografia é o principal fator que determina a distribuição de espécies, Magnusson et al. (2005) propõe o método RAPELD, que se baseia na utilização de parcelas de amostragem longas e estreitas, com seu maior eixo orientado ao longo das curvas de nível do terreno. Segundo eles, este desenho minimiza a variação interna na topografia em cada parcela, e permite seu uso como variável preditora das distribuições de espécies em mesoescala. Este método foi implantado e testado inicialmente na Amazônia (Costa et al. 2005), e vem sendo amplamente aplicado em outras regiões do Brasil. Entre elas está o módulo Pantanal Norte chamado de SALD (Sítio de Amostragem de Longa Duração), área de estudo deste trabalho.

Com a instalação do SALD em uma área inundável nas adjacências do rio Cuiabá, foi questionada a necessidade do monitoramento da inundação, pois a cota topográfica seria suficiente para o entendimento do padrão de biodiversidade (Magnusson et al. 2005) e na determinação da intensidade e duração da inundação (Neiff 1990, Neiff et al. 2005), por se tratar de variáveis espacialmente correlacionadas. No entanto, estudos recentes em planícies de inundação, indicaram que a complexidade geomorfológica da planície (presença de paleocanais, diques marginais e vegetação) afeta a dinâmica espacial da inundação (Poole et al. 2002, Fantin-Cruz 2008, Girard et al. 2010). A consequiência dessa complexidade é a ocorrência de locais da mesma cota topográfica com intensidade, duração e frequência de inundação diferentes, sendo estas relações e seus padrões espaciais o enfoque deste estudo.

Apesar da reconhecida influência da inundação na distribuição das unidades fitofisionômicas pantaneiras, não estão disponíveis trabalhos que abordem enfaticamente a avaliação sistemática de quais fatores acima citados (intensidade e duração da inundação e topografia) mais influenciam os padrões espaciais das fitofisionomias, principalmente no que se refere às relações com os elementos da paisagem, utilizando informações espacializadas (Zeilhofer \& Schessl 2000).

Desta forma, o presente trabalho tem os seguintes objetivos: i) caracterizar e quantificar a abrangência das unidades fitofisionômicas do SALD; ii) identificar as preferências ambientais de cada unidade; iii) avaliar a distribuição das fitofisionomias no gradiente de inundação (intensidade e duração) e topográfico e iv) observar se as relações detectadas a partir da sobreposição de mapas correspondem com as detectadas em escala de campo, contribuindo, portanto, no conhecimento geoecológico das paisagens pantaneiras e sua potencialidade como indicador das condições ambientais, tanto no que se refere às questões do manejo dos recursos naturais, quanto à proteção do solo e definição de habitats de animais silvestres.

\section{Material e Métodos}

\section{1. Área de estudo}

O Pantanal é uma planície sedimentar de cerca de $138.000 \mathrm{~km}^{2} \mathrm{em}$ território brasileiro, formada no período quaternário, preenchida com depósitos aluviais dos rios da Bacia do Alto Paraguai. O Alto Paraguai drena uma área perto de $500.000 \mathrm{~km}^{2}$ dos quais dois terços estão no Brasil, nos estados de Mato Grosso e Mato Grosso do Sul. De acordo com a elevação topográfica, a bacia pode ser subdividida em três unidades fisiográficas. Primeiro, o Planalto com altitudes entre 250 e 750 m, sendo ele uma região de cabeceiras. Em seguida, a Depressão, em altitudes variando de 180 a $250 \mathrm{~m}$, de relevo aplainado e uma pequena área com encostas íngremes. A última unidade é o Pantanal, com altitudes entre 100 a 180 m que apresenta um relevo baixo e plano com um gradiente hidráulico regional não superior a $15 \mathrm{~cm} \cdot \mathrm{km}^{-1}$. Sua hidrografia é formada por grandes rios, como o Paraguai, Cuiabá, São Lourenço, Piquiri, Taquari e Negro, entre outros. Esta complexa rede hidrográfica, em conjunto com diversos tipos de solo, dá origem a uma grande variedade de paisagens (DNOS 1974).

O clima regional é do tipo AW de Köppen, quente e úmido com chuvas no verão e estiagem no inverno. A pluviosidade oscila entre 800 e $1.400 \mathrm{~mm} / \mathrm{ano}$, sendo que $80 \%$ ocorrem entre os meses de novembro e março. A média anual de temperatura oscila entre um máximo de 29 a $32{ }^{\circ} \mathrm{C}$ e um mínimo de 17 a $20{ }^{\circ} \mathrm{C}$ (PCBAP 1997). Os solos são de origem sedimentar, ocorrendo em fases argilosa e arenosa de forma alternada e descontínua, com a dominância de solos hidromórficos compondo 92,5\% do total (Amaral Filho 1984).

O regime da inundação é monomodal com variações espaçotemporais. O início da inundação ao norte da planície coincide com o início de chuvas constantes no mês de dezembro, enquanto na parte central e sul da planície podem ocorrer defasagens de até 3 meses entre o pico das precipitações (fevereiro/março) e o máximo das inundações. Ao longo dos cursos dos rios, a inundação da planície é principalmente garantida pelo transbordamento dos mesmos a partir de canais intermitentes. Em locais distantes ou com pouca influência de curso de rio, as inundações podem ser também provocadas por chuvas locais (Penha et al. 1999).

É neste contexto que está inserido o Sítio de Amostragem de Longa Duração (SALD), localizada na parte norte do Pantanal, no município de Nossa Senhora do Livramento, Mato Grosso, e pertence à bacia do rio Cuiabá, afluente do rio Paraguai principal rio formador do Pantanal (Figura 1). O SALD abrange uma área total de $25 \mathrm{~km}^{2}$ $(5 \times 5 \mathrm{~km})$ e é submetida a um sistema misto, onde a inundação é uma combinação da chuva local, águas oriundas do Rio Cuiabá e áreas adjacentes (Fantin-Cruz 2008).

\section{Aquisição e tratamento dos dados}

Para mapeamento das unidades fitofisionômicas no SALD foi utilizada a classificação supervisionada (MAXVER) de uma imagem CBERS-2B, sensor CCD, bandas 2, 3 e 4, do dia 05 de setembro de 2007, adquirido junto ao Instituto Nacional de Pesquisas Espaciais - INPE. Para a classificação da imagem CBERS foram utilizados ao todo 40 áreas de treinamento, que correspondem a regiões de controle onde também foram feitas medições de intensidade e duração da inundação e medida de cota topográfica (Figura 1).

O monitoramento da inundação ocorreu semanalmente entre os dias 14 de dezembro de 2006 e 12 de junho de 2007. A intensidade da inundação foi estimada pela profundidade máxima da coluna de 


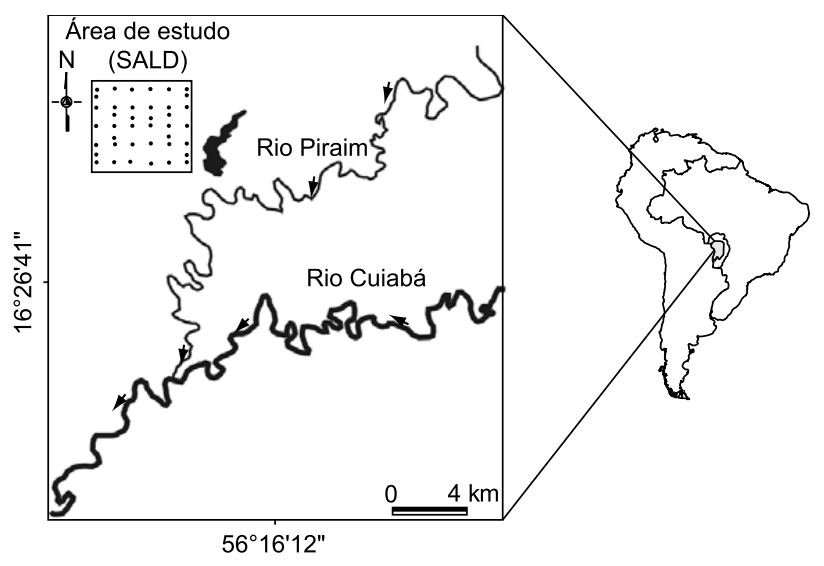

Figura 1. Localização do Sítio de Amostragem de Longa Duração (SALD), Pantanal, Brasil.

Figure 1. Location of the Long-Term Sampling Site (LTSS), Pantanal, Brazil.

água registrada durante o estudo e a duração estimada pelo tempo máximo de alagamento em número de dias. Os mapas de inundação e topografia foram gerados a partir da interpolação por krigagem ordinária com 40 amostras para a inundação e 200 para a topografia, para maiores detalhes ver Fantin-Cruz (2008). Os valores interpolados da intensidade, duração da inundação e topografia foram recodificados em três categorias ordinais de acordo com a Tabela 1 .

Para analisar as relações espaciais, o mapa de vegetação foi cruzado com os mapas de intensidade de inundação, duração da inundação e topografia aos pares. Cada cruzamento resultou em uma tabela de contingência, que apresenta a área de intersecção entre as classes cruzadas, nas quais cada mapa foi considerado como uma variável. A associação entre as variáveis da tabela foi verificada pelo teste de Qui-quadrado $\left(\mathrm{X}^{2}\right)$. Para os valores de $\mathrm{X}^{2}$ significativos foram calculados o coeficiente de correlação de Cramer $(\Phi)$. Este coeficiente varia de zero a um e foi utilizado como o indicativo de associação entre as variáveis cruzadas. O método descrito acima foi o mesmo seguido por Ruggiero et al. (2006).

Os pontos de controle foram, em seguida, utilizados na análise de variância não paramétrica (Kruskal-Wallis) para testar o efeito da inundação (intensidade e duração) e topografia sobre as unidades fitofisionômicas e observar se as relações ecológicas detectadas a partir da sobreposição de mapas mantiveram as relações identificadas na escala de campo.

Os procedimentos de classificação das unidades fitofisionômicas foram realizados no Spring 4.3.3 (INPE), já os cruzamentos de mapas foram efetuados no IDRISI Andes (Clark Lab).

\section{Resultados}

\section{Caracterização das unidades fitofisionômicas}

No SALD foram identificadas quatro unidades fitofisionômicas (Figura 2). Dentre elas, o Campo inundável (Savana gramíniolenhosa sazonalmente inundável) foi a unidade predominante cobrindo $56,4 \%$ da área, seguida pela Cordilheira (Savana arbórea densa com Curatella americana L. e Dpteryx alata Vogel.) com 23,0\%, Landizal (Floresta sempre verde sazonalmente inundável com Calophyllum brasiliense Camb.) com 10,5\% e Camabarazal (Floresta monodominante sazonalmente inundável de Vochysia divergens Pohl.) com 10,1\%.

O desempenho médio da classificação foi de $97,4 \%$ e confusão média de 2,6\%. Salienta-se que a validação refere-se à classificação
Tabela 1. Níveis de categorização dos mapas de intensidade e duração da inundação e topografia.

Table 1. Category levels of the maps of flood intensity and duration and topography.

\begin{tabular}{lccc}
\hline \multicolumn{1}{c}{ Parâmetros } & Baixa & Média & Alta \\
\hline Intensidade $(\mathrm{cm})$ & $0-20$ & $20-40$ & $40-60$ \\
Duração (dias) & $0-65$ & $65-130$ & $130-190$ \\
Topografia $(\mathrm{m})$ & $<113,5$ & $113,5-114,0$ & $>114,0$ \\
\hline
\end{tabular}

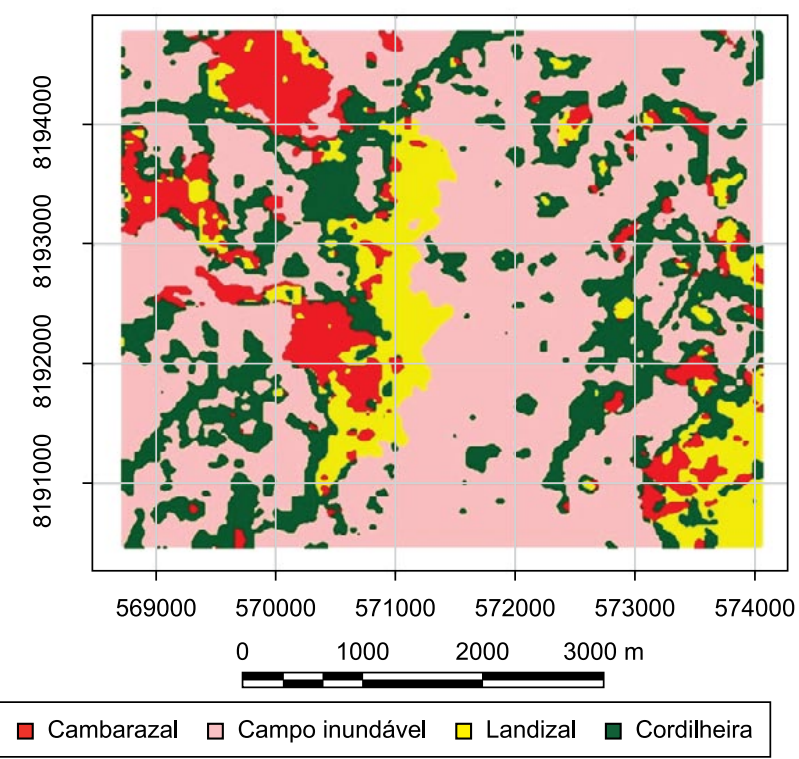

Figura 2. Mapeamento das unidades fitofisionômicas no Sítio de Amostragem de Longa Duração (SALD), Pantanal, Brasil.

Figure 2. Mapping of the phytophysiognomic units in the Long-Term Sampling Site (LTSS), Pantanal, Brazil.

das áreas de amostragem de campo, também utilizadas para extração das assinaturas espectrais. Classificações errôneas ocorrem principalmente entre as unidades fitofisionômicas Landizal e Cambarazal com confusão de $4,0 \%$.

\section{Topografia}

De modo geral, o SALD apresenta uma superfície inclinada no sentido NE/SO onde a menor cota topográfica medida foi de $112,52 \mathrm{~m}$ e a maior de 116,56 m, definindo uma variação topográfica de 4,04 m. A maior parte da área (43\%) encontra-se em altitudes superiores a 114,0 m (altas), seguido por 113,5 a 114,0 m em 40\% da área (médias) e 17\% em altitudes inferiores a 113,5 m (baixa; Figura 3).

\section{Inundação}

Durante o período de estudo, observa-se que o nível hidrométrico máximo do rio Cuiabá em Porto Cercado foi de 4,45 m (Figura 4), pouco inferior aos 4,54 $\mathrm{m}$ da média máximas anuais neste local.

Em relação à variação espacial das inundações, as maiores profundidades de água foram medidas no dia 23/02/07. Nesta data, a profundidade variou de zero a $63 \mathrm{~cm}$, quando $57,1 \%$ da área estavam inundadas com profundidades de 20 a $40 \mathrm{~cm}$ (média), seguida pelas regiões com profundidades de zero a $20 \mathrm{~cm}$ com $22,9 \%$ (baixa) e 40 a $60 \mathrm{~cm}$ com 9,2\% (alta; Figura 5a). Já a duração da inundação 


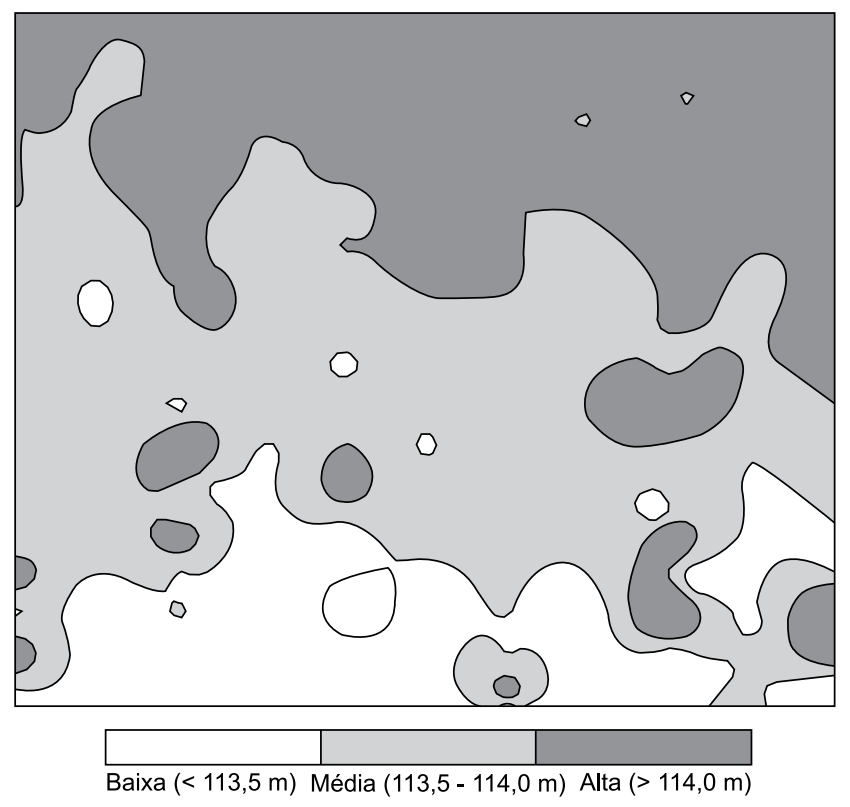

Figura 3. Superfície topográfica do Sítio de Amostragem de Longa Duração (SALD), Pantanal, Brasil.

Figure 3. Surface topography of the Long-Term Sampling Site (LTSS), Pantanal, Brazil.

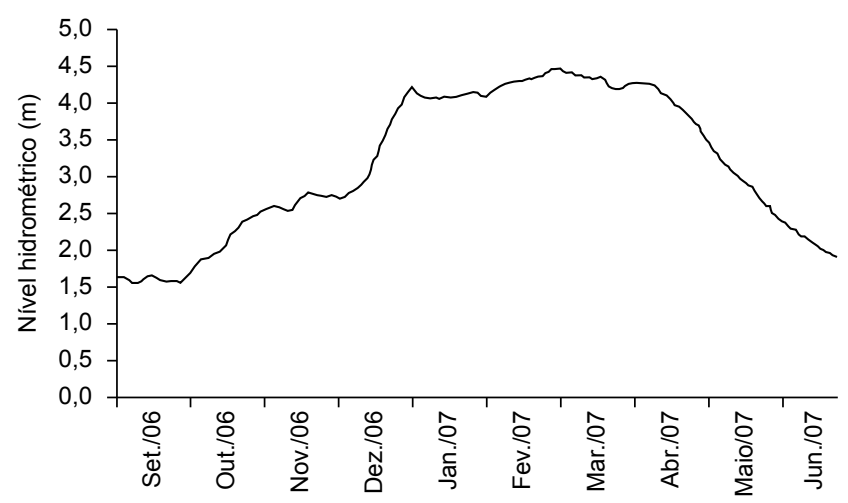

Figura 4. Hidrograma do rio Cuiabá em Porto Cercado do período de setembro de 2006 a julho de 2007.

Figure 4. Hydrogram of the Cuiabá River in Porto Cercado from September 2006 to July 2007.

variou espacialmente de zero a 195 dias. Cerca de $61 \%$ da área permaneceram inundadas entre 65 e 130 dias (média), 21\% com duração de inundação entre 130 a 195 dias (alta) e $17 \%$ de zero a 65 dias (baixa; Figura 5b).

\section{Relações entre intensidade e duração da inundação e topografia}

Para os pontos amostrais levantados em campo, foram obtidos modelos de regressão para a relação entre a cota topográfica e a duração da inundação (Figura 6a), cota com a intensidade da inundação (Figura 6b) e entre a intensidade e duração da inundação (Figura 6c). Apesar dos modelos serem significativos, a topografia pouco explica a variabilidade espacial da intensidade e duração da inundação (14 e 22\%, respectivamente), pois se observa uma grande
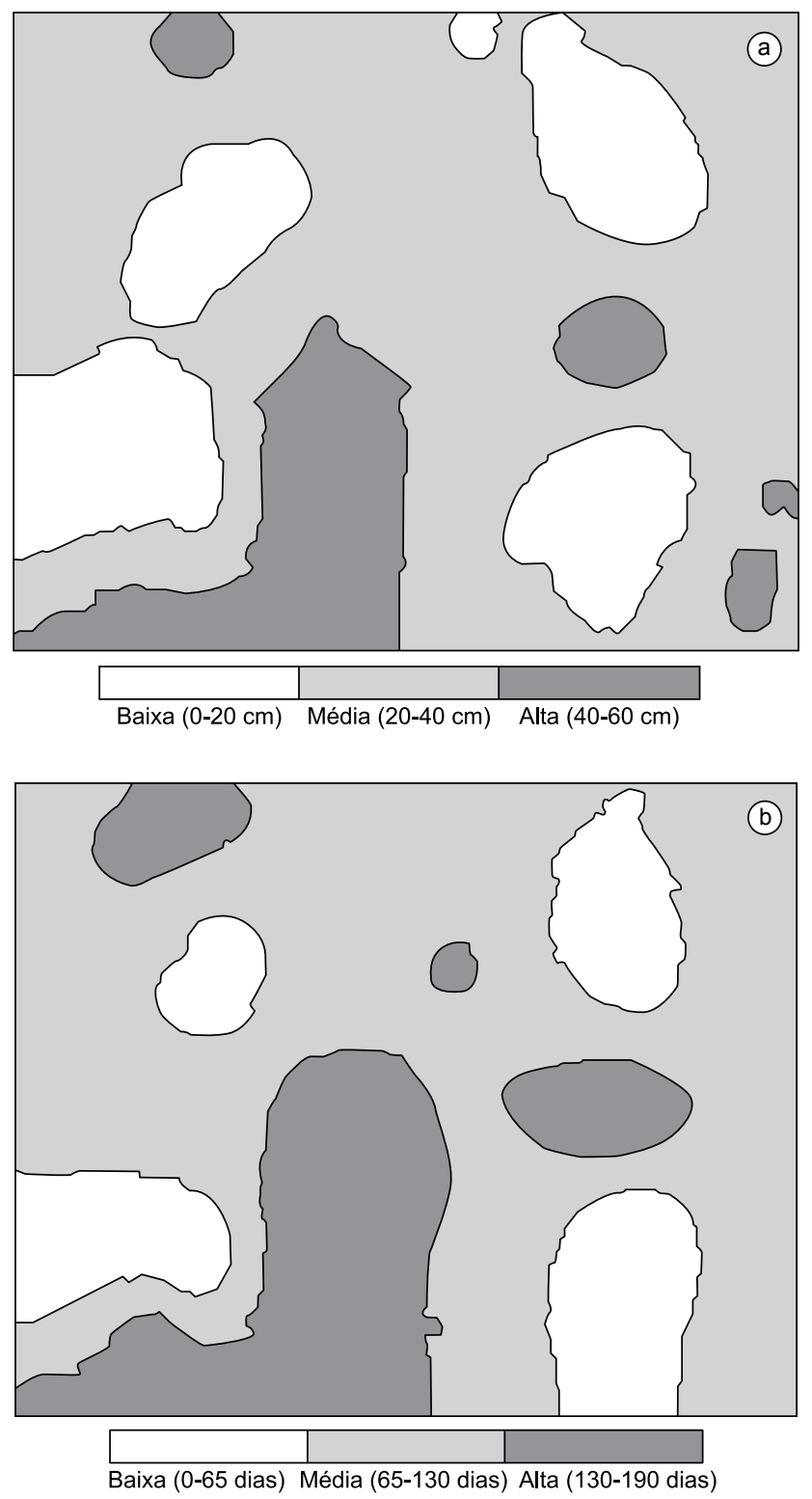

Figura 5. a) Mapeamento da intensidade e b) duração da inundação Sítio de Amostragem de Longa Duração (SALD), Pantanal, Brasil.

Figure 5. a) Mapping of flood intensity and b) duration in the Long-Term Sampling Site (LTSS), Pantanal, Brazil.

dispersão em torno da linha de tendência (Figura 6a, b). O mesmo não acontece com a relação entre a intensidade e duração, fatores que se mostraram fortemente correlacionados $\left(r^{2}=0,85\right)$.

\section{Relações entre fitofisionomia, inundação e topografia}

O conjunto dos mapas utilizados nos cruzamentos (Figuras 2, 3 e 5) permitiu a determinação da distribuição relativa das unidades fitofisionômicas nas classes categóricas de inundação (intensidade e duração) e topografia, representada na Figura 7. Nota-se que as unidades apresentam um nítido gradiente de distribuição entre os fatores analisados, com exceção do campo inundável. As preferências de ocorrência de cada unidade estão resumidas na Tabela 2. 

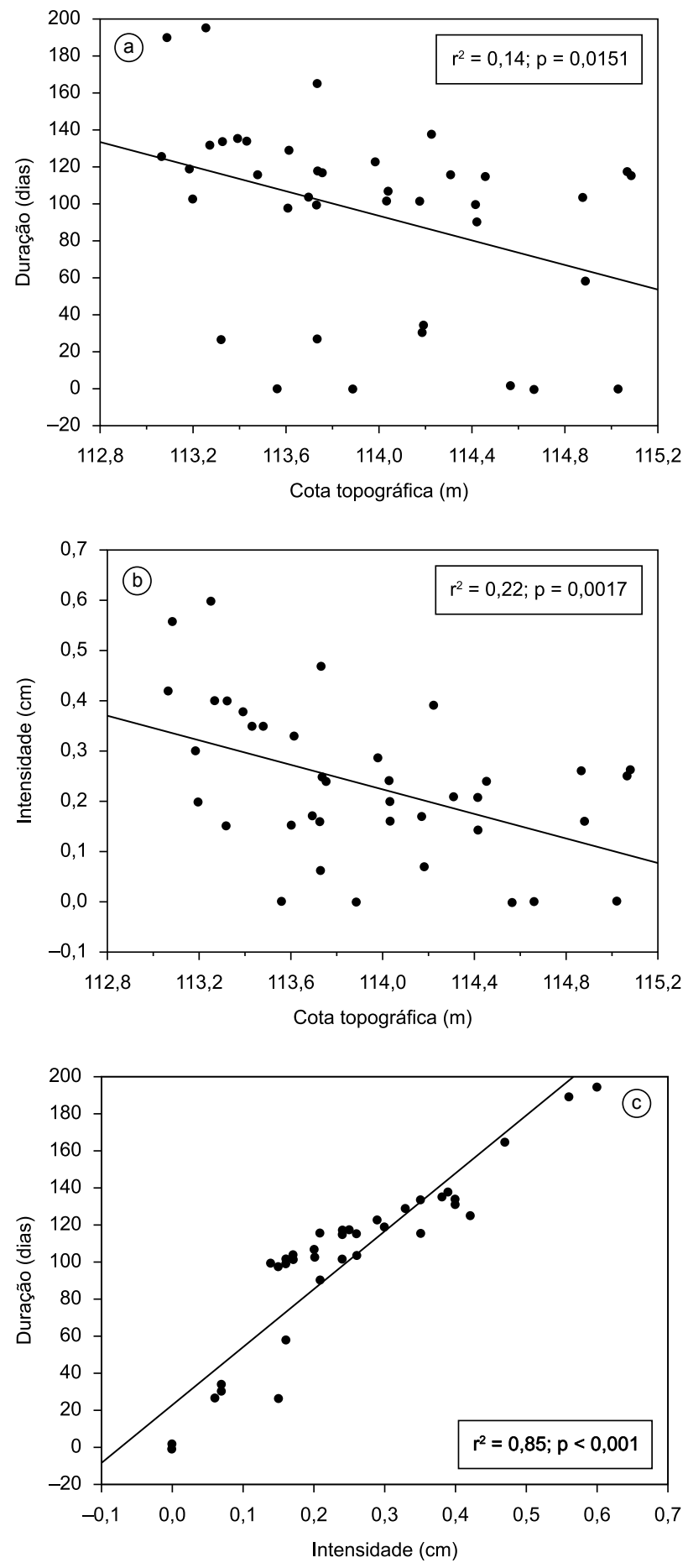

Figura 6. a) Relações entre a cota topográfica e a duração da inundação; b) cota topográfica e intensidade da inundação; e c) a intensidade e duração da inundação.

Figure 6. a) Relationships between the topographic quota and flood duration; b) topographic quota and flood intensity; and c) flood intensity and duration.

A tabulação cruzada dos valores categóricos extraídos dos mapas temáticos mostra valores de $\mathrm{X}^{2}$ significativos no nível de $5 \%$ (Tabela 3). O cruzamento que apresentou o maior valor de $\Phi$ (coeficiente indica o nível de associação entre as variáveis) foi entre a fitofisionomia e a intensidade da inundação $(\Phi=0,20)$. Hipotetizase que os valores geralmente baixos de $\Phi$, não são somente uma
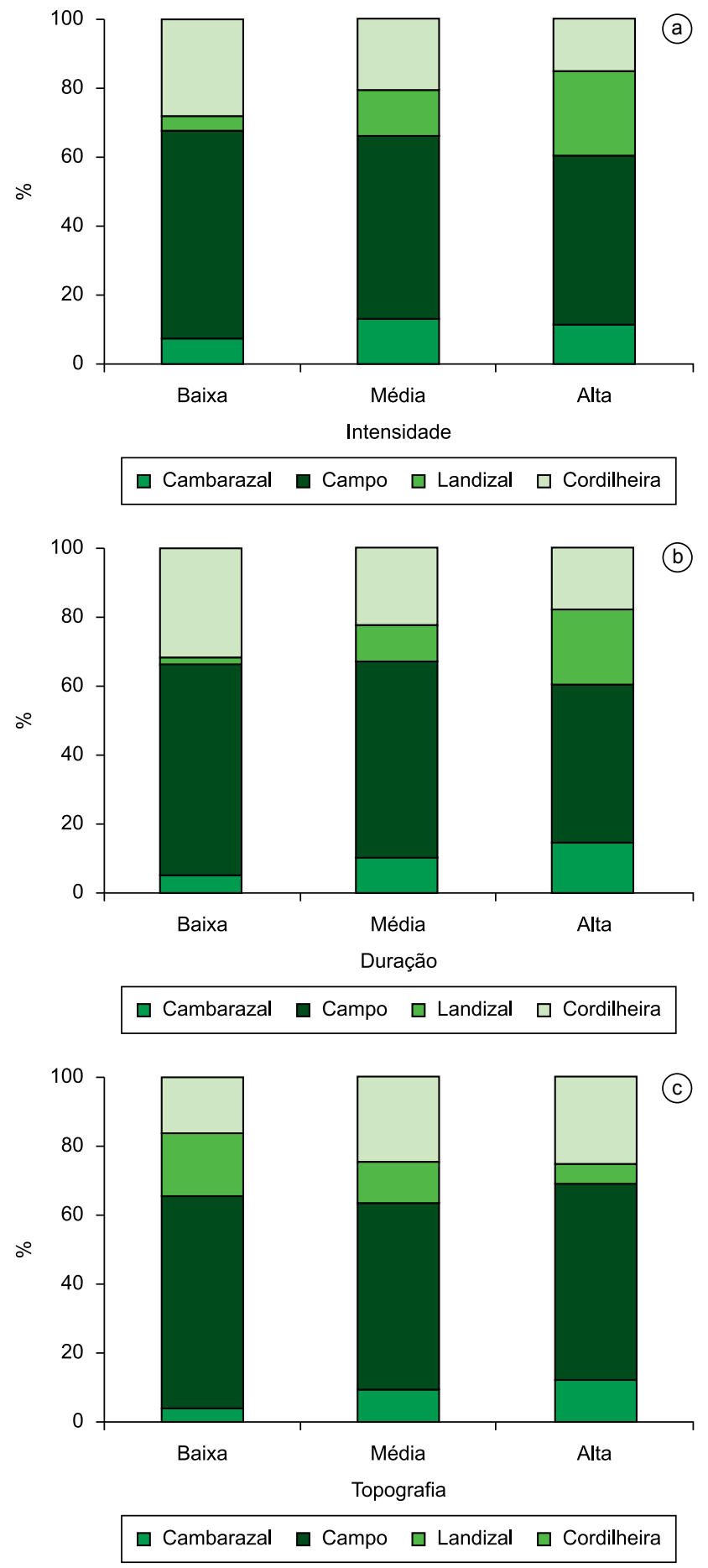

Figura 7. Distribuição relativa das unidades fitofisionômicas nos gradientes de: a) intensidade da inundação; b) duração da inundação; e c) topografia.

Figure 7. Relative distribution of the phytophysiognomic units in the gradients of: a) flood intensity; b) flood duration; and c) topography.

função de uma limitada relação entre as variáveis, mas também das incertezas nas camadas espaciais interpoladas, que, devido à amostragem limitada, não representam as oscilações das variáveis em microescala. Os resultados das análises das amostras pontuais seguiram o mesmo padrão obtidos pela sobreposição de mapas, visto que, o teste de Kruskal-Wallis indicou diferenças significativas na 
Tabela 2. Maior ocorrência das unidades fitofisionômicas em relação à inundação e topografia.

Table 2. Highest occurrence of phytophysiognomic units in relation to flooding and topography.

\begin{tabular}{lcccc}
\hline & Cambarazal & Campo & Landi & Cordilheira \\
\hline Intensidade & Média & Baixa & Alta & Baixa \\
Duração & Alta & Baixa & Alta & Baixa \\
Topografia & Alta & Baixa & BaIxa & Alta \\
\hline
\end{tabular}

Tabela 3. Valores de Qui-quadrado $\left(\mathrm{X}^{2}\right)$ obtidos dos três cruzamentos, graus de liberdade (GL) e o coeficiente de Cramer $(\Phi)$.

Table 3. Chi-square $\left(\mathrm{X}^{2}\right)$ values obtained from the three cross-references, degrees of freedom (DF), and Cramer's coefficient $(\Phi)$.

\begin{tabular}{lcccc}
\hline \multicolumn{1}{c}{ Cruzamentos } & $\mathbf{X}^{\mathbf{2}}$ & Gl & $\boldsymbol{\Phi}$ & $\mathbf{p}$ \\
\hline Fitofisionomia $\times$ Intensidade & 3221 & 8 & 0.20 & $<0.01$ \\
Fitofisionomia $\times$ Duração & 1775 & 8 & 0.15 & $<0.01$ \\
Fitofisionomia $\times$ Topografia & 1420 & 8 & 0.13 & $<0.01$ \\
\hline
\end{tabular}

distribuição das unidades fitofisionômicas da intensidade ( $p=0,014$; Figura 8a) e duração da inundação ( $p=0,037$; Figura $8 b$ ), porém não da cota topográfica $(p=0,093$; Figura $8 c)$. Com isso, podemos afirmar que a intensidade da inundação é o principal dos fatores avaliados que está influenciando a distribuição das unidades fitofisionômicas no SALD.

\section{Discussão}

No Pantanal, a heterogeneidade fitofisionômica tem sido relacionada às variações do relevo e topografia (Ponce \& Cunha 1993, Damasceno-Junior et al. 2005), à estrutura do solo (Zeilhofer \& Schessl 2000) e aos padrões espaço-temporal da inundação (Rebellato \& Cunha 2005, Arieira \& Cunha 2006). Para tais relações as informações foram provenientes de coletas pontuais ao longo de transectos. Levantamentos fitofisionômicos a partir de dados de sensoriamento remoto são comumente utilizados do Pantanal, onde se destacam os trabalhos de Silva et al. (2000) através de levantamento aéreo e de Cunha et al. (2006) através de imagens de satélite (LandsatTM). No entanto, esses trabalhos apenas mapearam e caracterizaram as fitofisionomias, sem estabelecer relações estatísticas com os elementos da paisagem.

O pequeno número (quatro) de unidades fitofisionômicas encontradas no SALD é reflexo da pequena área amostrada, quando comparada a complexidade geoecológica desta região da planície. Uma vez que, estudos realizados por Silva et al. (2000) em todo o Pantanal, identificaram 16 tipos de unidades vegetacionais, e Cunha et al. (2006), para uma região da parte norte do Pantanal (Município de Poconé), apontou 14 tipos, sendo dois destes classificados como sistemas secundários (pastagens artificiais, canaviais).

A distribuição das unidades fitofisionômicas no SALD foi influenciada mais fortemente por aspectos ligados à inundação e não à topografia. Geralmente os efeitos da intensidade e duração da inundação e da topografia são analisados de maneira conjunta, supondo uma forte correlação entre esses parâmetros. Este tipo de suposição, sem uma correta avaliação, pode levar a conclusões equivocadas, visto que estes fatores, conforme o grau de associação entre eles, podem ser considerados como independentes em modelos preditivos.
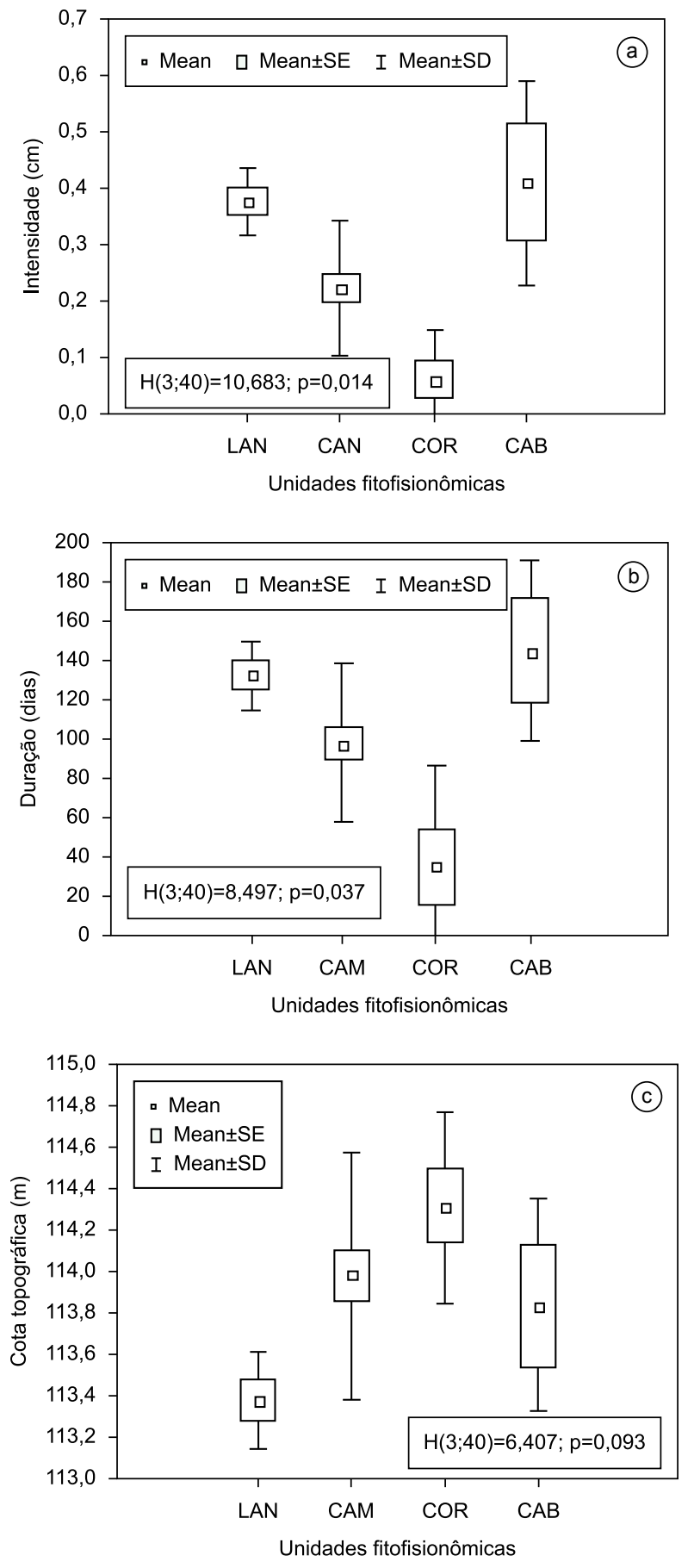

Figura 8. Análise de variância não paramétrica (Kruskal-Wallis) entre as unidades fitofisionômicas e: a) intensidade da inundação; b) duração da inundação; e c) cota topográfica $(\mathrm{CAB}=$ Cambarazal, $\mathrm{CAM}=\mathrm{Campo}$, $\mathrm{COR}=$ Cordilheira, $\mathrm{LAN}=$ Landizal $)$.

Figure 8. Nonparametric analysis of variance (Kruskal-Wallis) among the phytophysiognomic units and: a) flood intensity; b) flood duration; and c) topographic quota $(\mathrm{CAB}=\mathrm{Cambarazal}, \mathrm{CAM}=\mathrm{Campo}, \mathrm{COR}=$ Cordilheira, LAN = Landizal).

Em estudos florísticos e fitofisionômicos realizados na Amazônia, comumente são observadas mudanças de composição e abundância ao longo de gradientes topográficos, onde associam aos locais topograficamente mais baixos as maiores durações e intensidades de inundação e aos locais mais altos um padrão inverso (Ferreira 
2000, Cattanio et al. 2002, Ferreira \& Almeida 2005). Vale ressaltar que a intensidade da inundação na Amazônia pode chegar a $14 \mathrm{~m}$ (Ferreira 2000), resultando supostamente em boas relações entre a inundação e a topografia.

No SALD, a baixa declividade do terreno associada a uma vegetação densa e contínua impõe ao escoamento uma elevada rugosidade que ocasiona as grandes diferenças locais na intensidade e duração da inundação. Neste aspecto, observa-se que os padrões espaciais das formas geomorfológicas determinam os padrões espaciais da inundação, formando um sistema hidrodinamicamente complexo. $\mathrm{O}$ efeito da geomorfologia sobre o padrão espacial da inundação também foi registrado por Poole et al. (2002) na planície de inundação do Nyak (EUA), Casco et al. (2005) na planície de inundação do baixo Paraguai (Argentina) e por Girard et al. (2010) para o Pantanal.

Neste contexto, ressalta-se a importância de um monitoramento espacializado da inundação no SALD, pois neste, a utilização da cota topográfica em mesoescala como variável preditora para a distribuição de populações animais e vegetais, conforme recomendado por Magnusson et al. (2005) seria imprópria, especialmente se a ecologia dos organismos estiverem ligadas a fatores hídricos. Uma vez que cotas topográficas semelhantes podem apresentar variações de intensidade de inundação de até $40 \mathrm{~cm}$, considerada alta para uma área com valores máximos de inundação de $63 \mathrm{~cm}$. Esta fraca correlação permitirá aos trabalhos futuros a formulação de novas hipóteses sobre os determinantes da distribuição espacial das comunidades biológicas, o que não seria possível em áreas onde os dois fatores se correlacionam fortemente.

De forma geral, as diferenças locais na inundação se refletem na distribuição das unidades fitofisionômicas na área de estudo. Como salientado por Junk et al. (1989), a inundação condiciona o espectro biológico da vegetação, pois longos períodos de inundação podem produzir estresse hídrico nas plantas como conseqüência da falta de oxigênio nas raízes, favorecendo espécies mais adaptadas a essas condições.

Os mapeamentos e sua sobreposição indicam uma predominância de formações herbáceas em toda a área de estudo, independente da intensidade e duração da inundação e da sua posição topográfica. Isso ocorre devido ao fato da área de estudo estar inserida em uma região parcialmente antropizada pela criação extensiva de gado, onde a limpeza e o plantio de pastos é uma prática comum, modificando a distribuição natural das fisionomias vegetais, principalmente na expansão do campo inundável que serve de alimento para o gado. Diferentemente, as três formações lenhosas apresentam distribuições naturais com mais claro condicionamento aos padrões da inundação. Vale ressaltar que Zeilhofer \& Schessl (2000) mostraram que além da inundação aqui avaliada, os tipos de solo, principalmente a sua estrutura, apresentam efeito significativo na distribuição das unidades fitofisionômicas no Pantanal.

Quando se compara a maior área de ocorrência das unidades fitofisionômicas em cada fator, observou-se que houve uma fraca sobreposição das curvas de distribuição espacial que compõe o padrão da vegetação. Ou seja, a probabilidade da vegetação resistir às inundações determina a persistência do padrão fitofisionômico que é reflexo das condições hidrológicas médias encontradas em cada área ao longo do tempo (Mitsch \& Gosselink 2000).

As relações observadas em escala espacial correspondem com as feitas em escala pontual, isto é, os processos ecológicos que regem este padrão não se alteram entre as duas escalas avaliadas. Isso indica que as condições de inundação as quais cada unidade é submetida podem ser inferidas a partir de imagens de satélite ou técnicas de estimação espacial. Estas constatações feitas em mesoescala devem ser avaliadas em outras regiões do Pantanal a fim de verificar se os padrões hidroecológicos encontrados no SALD são válidos para outros compartimentos da planície.
Assim, este trabalho evidenciou a existência de quatro unidades fitofisionômicas, entre elas o Campo inundável foi o que apresentou maior área de ocorrência, seguido pelas Cordilheiras, Landizal e Cambarazal, respectivamente. Cada unidade apresentou distribuições distintas, onde primeiramente a intensidade e em segundo lugar a duração da inundação foram identificadas como os fatores relacionados com a estruturação mesoescala tanto espacial (sobreposição de mapas) quanto local (amostras pontuais) das unidades fitofisionômicas no Pantanal norte.

\section{Agradecimentos}

Ao CNPq pela bolsa de estudo ao primeiro autor. Ao Centro de Pesquisa do Pantanal (CPP) e ao Programa de Pesquisa Ecológico de Longa Duração (PELD-12) pelo apoio logístico. A Dra. Maria Luiza Porto, Dr. José Arenas Ibarra (Pepe) e aos revisores pelas contribuições e correções.

\section{Referências Bibliográficas}

AMARAL FILHO, Z.P. 1984. Solos do Pantanal Mato-Grossense. In Anais do X Simpósio sobre recursos naturais e socioeconômicos do Pantanal. EMBRAPA-CPAP-UFMS, 265p. (EMBRAPA-CPAP, Documentos, 5).

ARIEIRA, J. \& CUNHA, C.N. 2006. Fitossociologia de uma floresta inundável monodominante de Vochysia divergens Pohl (Vochysiaceae), no Pantanal Norte, MT, Brasil. Acta bot. bras. 20(3):569-580.

CASCO, S.L., CHIOZZI, N.I.B. \& NEIFF, J.J. 2005. La vegetacion como indicador de la Geomorfologia Fluvial. Rev. bras. geomorfol. 1:123-136.

CATTANIO, J.H., ANDERSON, A.B. \& CARVALHO, M.S. 2002. Floristic composition and topographic variation in a tidal floodplain forest in the Amazon Estuary. Rev. bras. Bot. 25(4):419-430.

COSTA, F.R.C., MAGNUSSON, W.E. \& LUIZAO, R.C. 2005. Mesoscale distribution patterns of Amazonian understorey herbs in relation to topography, soil and watersheds. J. Ecol. 93(5):863-878.

CUNHA, C.N. \& JUNK, W.J. 2001. Distribution of wood plant communities along the flood gradient in the Pantanal of Poconé, Mato Grosso, Brazil. Int. J. ecol. environ. Sci. 27:63-70.

CUNHA, C.N., JUNK, W.J. \& LEITÃO-FILHO, H.F. 2007. Woody vegetation in the Pantanal of Mato Grosso, Brasil: a preliminary typology. Amazoniana 19(3-4):159-184.

CUNHA, C.N., RAWIEL, P., WANTZEN, K.M., JUNK, W.J. \& PRADO, A.L. 2006. Mapping and characterization of vegetation units by means of Landsat imagery and management recommendations for the Pantanal of Mato Grosso (Brazil), north of Poconé. Amazoniana 19(1-2):1-32.

DAMASCENO-JUNIOR, G.A., SEMIR, J., SANTOS, F.A.M. \& LEITÃOFILHO, H.F. 2005. Structure, distribution of species and inundation in a riparian forest of Rio Paraguai, Pantanal, Brazil. Flora 200(2):119-135.

Departamento Nacional de Obras de Saneamento - DNOS. 1974. Estudos hidrológicos da Bacia do Alto Paraguai. Rio de Janeiro, 284 p. (Relatório Técnico UNESCO/PNUD).

FANTIN-CRUZ, I. 2008. Dinâmica da inundação em mesoescala na planície de inundação do rio Cuiabá - Brasil. Dissertação de mestrado, Universidade Federal de Mato Grosso, Cuiabá.

FERREIRA, L.V. \& ALMEIRA, S.S. 2005. Relação entre a altura de inundação, riqueza específica de plantas e o tamanho de clareiras naturais em uma floresta inundável de igapó, na Amazônia central. Ver. Árvore 29(3):445-453.

FERREIRA, L.V. 2000. Effects of flooding duration on species richness, floristic composition and forest structure in river margin habitat in Amazonian blackwater floodplain forests: implications for future design of protected areas. Biodivers. Conserv. 9(1):1-14.

GIRARD, P., FANTIN-CRUZ, I., OLIVEIRA, S.M.L. \& HAMILTON, S.K. 2010. Small-scale spatial variation of inundation dynamics in a floodplain of the Pantanal (Brazil). Hydrobiologia 638(1):223-233. 
JUNK, W.J., BAILEY, P.B. \& SPARKS, R.E., 1989. The flood pulse concept in river-floodplain systems. Can. J. Fish. aquat. Sci. 106:110-127.

MAGNUSSON, W.E., LIMA, A.P., LUIZÃO, R., LUIZÃO, F., COSTA, F.R.C., CASTILHO, C.V. \& KINUPP, V.F. 2005. RAPELD: A modification of the Gentry method for biodiversity srveys in long-tern ecological research sites. Biota Neotrop. 5(2): http://wwww.biotaneotropica.org.br/v5n2/pt/ astract?point-of-view+bn01005022005 (último acesso em 14/07/2009).

MITSCH, W.J. \& GOSSELINK, J.G. 2000. Wetlands. 4 ed. Van Nostrand Reinhold, New York, 920p.

NEIFF, J.J. 1990. Ideas for an ecological interpretation of the Paraná. Interciencia 15(6):424-441.

NEIFF, J.J. 2001. Humedales de la Argentina: sinopsis, problemas y perspectivas futuras. In El Agua en Iberoamerica, Funciones de los humedales, calidad de vida y agua segura (A.F. Cirelli, ed.). CYTED, Argentina, p. 83-112.

NEIFF, J.J., CASCO, S.L. \& ORFEO, O. 2005. Método para la medición de la conectividad entre procesos hidrológicos y geomorfológicos en ríos entrelazados. Rev. bras. geomorf. 6(1):75-83.

PCBAP. 1997. Diagnostico dos meios físico e biótico. Projeto Pantanal, Programa Nacional do Meio Ambiente. Plano de Conservação da Bacia do Alto Paraguai. MMA/PNMA, Brasília, 433p.

PENHA, J.M., DA SILVA, C.J. \& BIANCHINI, I. 1999. Productivity of the aquatic macrophytes Pontederia lanceolata Nutt. (Pontederiaceae) on the floodplains of the Pantanal Mato-grossense, Brazil. Wetl. Ecol. Mgmt. 7(3):155-163.
PONCE, V.M. \& CUNHA, C.N. 1993. Vegetated eartmounds in tropical savannas of Central Brazil: a synthesis With special reference to the Pantanal do Mato Grosso. J. Biogeogr. 20:219-225.

POOLE, G.C., STANFORD, J.A., FRISSEL, C.A. \& RUNNING, S.W. 2002. Three-dimensional mapping of geomorphic controls on floodplain hydrology and connectivity from aerial photos. Geomorphology 48(4):329-347.

REBELLATO, L. \& CUNHA, C.N. 2005. Efeito do "fluxo sazonal mínimo da inundação" sobre a composição e estrutura de um campo inundável no Pantanal de Poconé MT, Brasil. Acta. Bot. Bras. 19(4):789-799.

RUGGIERO, P.G.C., PIVELLO, V.R., SPAROVEK, G., TERAMOTO, E. \& PIRES NETO, A.G. 2006. Relação entre solo, vegetação e topografia em área de cerrado (Parque Estadual de Vassununga, SP): como se expressa em mapeamentos? Acta Bot. Bras. 20(2):383-394.

SILVA, M.P., MAURO, R.A., MOURÃO, G.M. \& COUTINHO, M.E. 2000. Distribuição e quantificação de classes de vegetação do Pantanal através de levantamento aéreo. Rev. Bras. Bot. 23(2):143-152.

ZEILHOFER, P. \& SCHESSL, M. 2000. Relationship between vegetation and environmental conditions in the Northern Pantanal of Mato Grosso, Brazil. J. Biogeogr. 27(1):159-168.

Recebido em 23/10/09

Versão reformulada recebida em 25/02/10

Publicado em 07/04/10 